Збірник наукових прачь Державного науково-дослідного інституту випробувань і сертифікачії озброєння та військової техніки. 2019. Вип. № 2

ISSN 2706-7386

Денисов Ю.О. Державний науково-дослідний інститут випробувань $i$ сертифікації озброєння та військової техніки

\title{
ВПЛИВ ПУЛЬСАЦІЙ НА ПОСТІЙНУ ІНТЕГРУВАННЯ РЕГУЛЯТОРА КОНТУРА СТРУМУ В СИСТЕМІ ЕЛЕКТРОПРИВОДУ КВАДРОКОПТЕРА
}

Виконано аналіз рівня пульсацій напруги на вході системи управління квазірезонансним імпульсним перетворювачем щчо перемикається при нульовому струмі (КРІП-ПНС). Він регулює напругу на вході автономного інвертора напруги (АІН) в системі електроприводу безпілотного літального апарату (БпЛА). Отримано співвідношення між постійною інтегрування регулятора контура струму та нескомпенсованою постійною, при якому пульсаиї на вході системи управління КРІП-ПНС мінімальні. 3 умові налагодження регулятора контура струму на процес кінцевой тривалості встановлено оптимальне значення цьього співвідношення.

Ключові слова: дискретність, пульсачії струму, Z-перетворення, контур струму, оптимізація, безколекторний двигун постійного струму.

В останні роки багато уваги приділяється удосконаленню основних характеристик безпілотних літальних апаратів, що $\epsilon$ актуальною темою розробок багатьох наукових колективів та фірм розробників. Силові установки сучасних малогабаритних БпЛА будуються на основі енергоефективних безколекторних двигунів постійного струму.

У системах електроприводу БпЛА на основі безколекторних двигунів постійного струму (БДПС) існує необхідність врахування впливу пульсацій вхідного струму АІН на постійну інтегрування регулятора контуру струму при його налагодженні на процес кінцевої тривалості. Від датчика струму пульсації надходять на вхід контуру струму та далі - на вхід системи управління КРІП-ПНС, що впливає на її динамічний коефіцієнт підсилення. Для зниження цього впливу на виходах датчика струму і регулятора контуру струму необхідно вмикати фільтри, що призводить до появи нескомпенсованої постійної часу, яка вносить затримку в процес керування. 3'являється проблема встановлення співвідношення між нескомпенсованою постійною та постійною інтегрування контуру струму, при якому виконується умова процесів кінцевої тривалості.

\section{Аналіз основних досліджень та публікацій}

У процесі модернізації та вдосконалення БпЛА вирішується проблема удосконалення електроенергетичних систем управління [1] на основі БДПС [2]. На теперешний час БДПС знайшли ефективне використання у промисловому [3] та в прецизійному [4] електроприводі. При побудові електроприводів на основі БДПС основна увага приділяється енергоефективності [5], [6], [7] та структурній побудові [8] для забезпечення високого рівня динамичних характеристик і мінимальных пульсацій моменту. Однак у відомих публікаціях не досліджено вплив пульсацій вхідного струму комутатора БДПС на параметри регулятора контура струму при його налагодженні на процес кінцевої тривалості.

Метою статті $є$ вирішенння цього питання на основі дискретних методов аналізу, які дозволяють найбільш повно врахувати специфіку дискретної системи електроприводу БпЛА.

\section{Пульсації струму на виході АІН}

Проведені дослідження показали, що вхідний струм AIH (рис. 1), пульсує з періодом $T_{0}=\frac{T}{6}$. Його форма пилкоподібна, вона залежить від параметру $\alpha=\frac{T R}{L}$, де $\mathrm{R}-$ активний опір обмотки фази БДПC, L - iї індуктивність T - період фазної напруги AIH. 


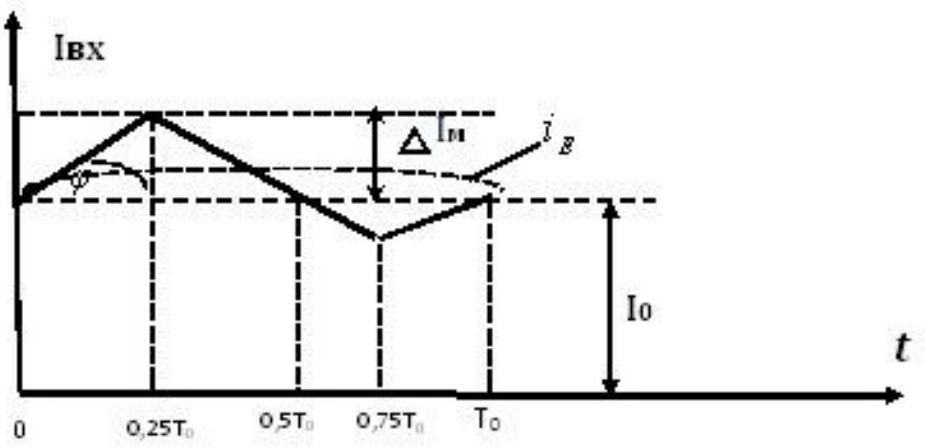

Рис.1 Вхідний струм АІН,

де: $\mathrm{I}_{0}$-постійна складова вхідного струму $\mathrm{AIH}, \Delta I_{M}$-амплитуда пульсацій вхідного

струму, $i_{E}-$ пульсаційна складова вхідного струму АІН, що викликана пульсаціями проти-е.р.с БДПС.

Окрім пульсацій вхідного струму на процеси в контурі струму впливають пульсації проти-е.p.c, які з'являються в результаті випрямління фазних е.р.с. обмоток БДПС, вони пульсують $з$ тією ж частотою, що і пульсації вхідного струму; по формі повторюють ділянки сінусойдальної е.p.c., модулюючи (по амплітуді) напругу, яка поступає на вхід АІН. Це породжує відповідну пульсаційну складову вхідного струму, яка синфазна з пилкою вхідного струму, на рис.1 вона зображена пунктиром. Існуючий підхід до врахування впливу пульсацій на коефіціент підсилення системи управління зв'язаний 3 корекціею його значення за допомогою фактору пульсацій. Такий підхід враховує відхилення вхідного сигналу системи управління від статичного режиму в нескінченно малому диапазоні. Процес запуску системи електроприводу від початку запуску до його закінчення $\epsilon$ перехідним зі значним відхиленням сигналу на вході системи управління, тому відомий метод для врахування впливу пульсацій на систему електроприводу призводить до значної похибки. Для вирішення питання вибору оптимального значенняя постійну інтегрування 3 врахуванням впливу пульсацій необхідно зменшити їх рівень до мінімальних значень за допомогою включенння фільтрів на виходах датчика струму і регулятора контуру струму. Внаслідок цього в контурі струму з'являється ланцюг з передатною функцією $K_{H}=\frac{1}{p T_{H}+1}$, де $T_{H}$ - нескомпенсована постійна, тому що регулятор струму налагоджується на компенсацію тільки електричної складової. Цей ланцюг вносить затримку в процес керування, що обмежує область стійкості системи. Рівень пульсацій на вході системи управління можна знизити за рахунок збільшення постійної інтегрування, що також збільшує затримку в системі регулювання. Необхідно знайти раціональне співвідношення між постійною інтегрування регулятора та нескомпенсованою постійною часу, за яким забезпечується мінімальний вплив пульсації на коефіциент підсилення системи управління, що забезпечує високу швидкодію системи електроприводу БпЛА з достатнім запасом стійкості.

\section{Вплив пульсацій вхідного струму АІН на рівень вихідних пульсації напруги регулятора контуру струму.}

Система електроприводу БпЛА виконана на основі БДПС, який живиться від акумуляторної батареї. Силовий регулятор-квазірезонансний імпульсний перетворювач, що перемикається при нульовому струмі (КРІП-ПНС). Структурна схема контуру струму представлена на рисунку 2. 


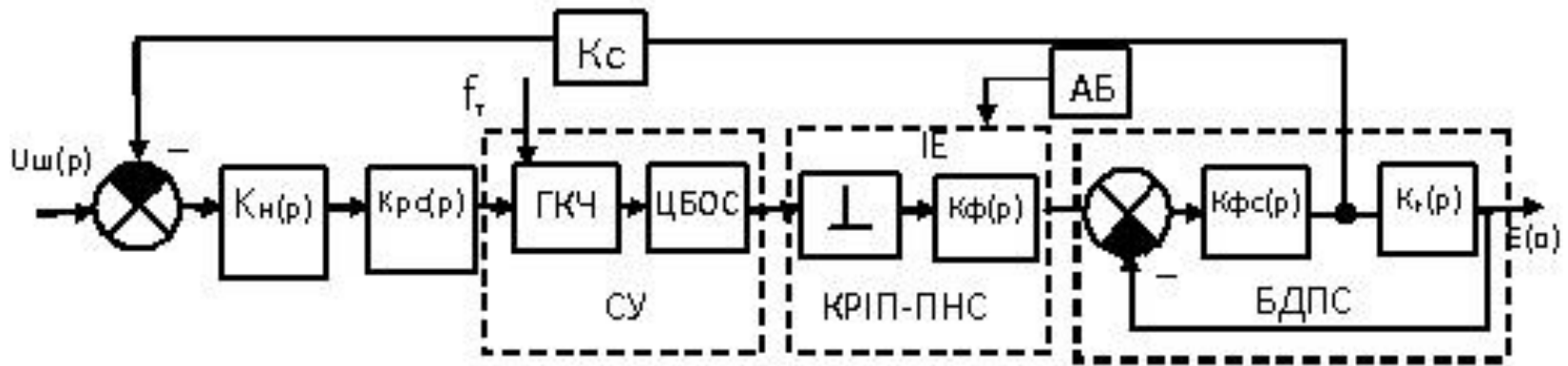

Рис.2 Структурна схема контуру струму,

де: $K_{\Phi}(p)=\frac{1-e^{-p T_{0}}}{p}, K_{H}(p)=\frac{1}{p T_{H}+1}, K_{P C}(p)=\frac{\left(1+p T_{E}\right)}{p T_{C}}, K_{\Phi C}(p)=\frac{1}{R\left(p T_{E}+1\right)}$,

$K_{E}(p)=\frac{R}{p T_{M}}-$ передатні функції нескомпенсованої постійної фіксатора нульового порядку,

регулятора контуру струму ланцюга, що формує струм та ланцюга, що формує проти-е.p.c. $\mathrm{U}_{\text {ш }}(\mathrm{p})$-вихідний сигнал контуру швидкості.

Система управління реалізує частотний принцип регулювання вихідної напруги КРІП-ПНС. Вона складається з генератора, що керується частотою ГКЧ цифрового блоку обробки сигналу (ЦБОС), на його вхід надходить сигнал з виходу регулятора контуру струму. На виході ГКЧ формується сигнал, частота якого залежить від вхідного сигналу. Цифровий блок включає в себе логічні схеми для перетворення сигналів з виходу ГКЧ в імпульси постійної тривалості для керування транзистором КРІП-ПНС. Переналагодження частоти імпульсів з виходу ЦБОС виконується з постійної тактовою частотою:

$$
f_{T}(p)=\frac{1}{T_{0}} .
$$

На структурній схемі КРІП-ПНС представлено ідеальним імпульсним елементом (IE) та формуючим елементом-фіксатором нульового порядку, тому що постійна напруга на виході формуючого елемента змінюється з постійною тактовою частотою. Пульсації, які надходять від датчика струму на вхід ГКЧ через нескомпенсований ланцюг та регулятор струму, будуть впливати на коефіцієнт підсилення системи управління. Для мінімізації цього впливу необхідно довести до мінімуму рівень пульсацій з виходу регулятора контуру струму, що можливо за рахунок вибору відповідного значення співвідношення між постійною часу нескомпенсованого ланцюга та постійною інтегрування.

При визначенні рівня пульсацій на виході ГКЧ впливом “модулюючого" ефекту від проти-е.р.с. БДПС нехтуємо, враховуємо лише пилкоподібну форму змінної складової його вхідного струму, рис.1. Сигнал з виходу датчика струму можна представити набором лінійних функції.

$$
U_{B h X}(t)=K_{C}[K \cdot(t)-2 K(t-0.25 T)+2 K 1(t+0.75 T)-K(1-T)],
$$

де $K=\operatorname{tg} \phi=\frac{I_{M}}{0.25 T}$, Оскільки зображення вихідного сигналу регулятора контуру струму

$$
\begin{gathered}
U_{P C}(p)=U_{B X}(p) \frac{\left(1+p T_{E}\right) K c}{\left(p T_{H}+1\right) p T_{C} K_{C} K_{C Y}}, \text { то } \\
U_{B X}(p)=K K_{C} \frac{1-2 e^{-0.25 p T}+2 e^{-0.75 p T}-e^{-p T}}{p^{2}} .
\end{gathered}
$$

Переходячи до відносної комплексної змінної $q=p T$, отримаємо:

$$
U_{P C}(q)=\frac{K K_{C}}{T} \frac{1-2 e^{-0.25 q}+2 e^{-0.75 q}-e^{-q}}{\frac{q}{T^{2}}} \cdot \frac{1+q \overline{T_{E}}}{T_{H^{(}\left(\frac{q}{T^{2}}+\frac{1}{T_{H}}\right) \frac{q}{T} T_{T}} .}
$$


Після перетворень

$$
U_{P C}(q)=\frac{K K_{C}}{T} \frac{1-2 e^{-0.25 q}+2 e^{-0.75 q}-e^{-q}}{\frac{q}{T^{2}}} \cdot \frac{1+q \overline{T_{E}}}{T_{H}\left(\frac{q}{T^{2}}+\frac{1}{T_{H}}\right) \frac{q}{T} T_{T}},
$$

де $K_{0}=\frac{R I_{M} T^{2}}{0.25 T_{T} T_{H}}, \beta=\frac{T}{T_{H}}, \overline{T_{E}}=\frac{T}{T_{E}}$.

Представимо (1) у вигляді:

$$
\begin{aligned}
& U_{P C}(q)=K_{0}\left(1-2 e^{-0.25 q}+2 e^{-0.75 q}-e^{-q}\right) \times \\
& \times\left(\frac{B_{1}}{q^{3}}+\frac{B_{2}}{q^{2}}+\frac{B_{3}}{q}+\frac{B_{4}}{q+\beta}\right),
\end{aligned}
$$

де $B_{1}=\frac{1}{\beta}, B_{2}=-\frac{1-\beta \bar{T} \ni}{\beta^{2}},{ }_{3}=\frac{1-\beta \bar{T} \ni}{\beta^{3}}, B_{4}=-\frac{1-\beta \bar{T} \ni}{\beta^{3}}$.

Знайдемо модіфіковане Z-перетворення (2), враховуючи, що

$$
Z_{M}\left[\frac{2 !}{q^{3}}\right]=\frac{Z(Z+1)}{(Z-1)^{3}}+\frac{2 Z \varepsilon}{(Z-1)^{2}}+\frac{Z \varepsilon^{2}}{Z-1} ; Z_{M}\left[\frac{1}{q^{2}}\right]=\frac{Z}{(Z-1)^{2}}+\frac{Z \varepsilon}{Z-1} ; Z_{M}\left[\frac{1}{q}\right]=\frac{Z}{Z-1} ; Z_{M}\left[\frac{1}{q+\beta}\right]=\frac{Z e^{-\beta \varepsilon}}{Z-e^{-\beta}} .
$$

При знаходженні модифікованого $\mathrm{Z}$ перетворення (2) використаємо теорему множеня на $F^{*}(Z, \varepsilon)$, згідно якої $e^{-\gamma q}$ для $0 \leq \varepsilon \leq \gamma$ функція $F^{*}(Z, \varepsilon)$ помножується на $Z^{-1}$, а $\varepsilon=\varepsilon+1-\gamma$ . Для $0 \leq \varepsilon \leq \gamma$ множення на $Z^{-1}$ відсутне, а $\varepsilon=\varepsilon-\gamma$

Після перетворень маємо результати модифікованого Z-перетворення (2) для інтервалів зміни струму пилкоподібної форми:

$$
\begin{aligned}
& U_{P C}^{*}(z, \varepsilon)=\frac{K_{0}\left(1-\beta \overline{T_{E}}\right)}{\beta^{3}}\left[1-\frac{z e^{-\beta \varepsilon}-2 e^{-\beta(\varepsilon+0.75)}+2 e^{-\beta(\varepsilon+0.25)}-e^{-\beta \varepsilon}}{z-e^{-\beta}}\right] \\
& \text { при } 0 \leq \varepsilon \leq 0,25 \text {; } \\
& U_{P C}^{*}(z, \varepsilon)=\frac{K_{0}\left(1-\beta \overline{T_{E}}\right)}{\beta^{3}}\left[-1-\frac{z e^{-\beta \varepsilon}-2 e^{-\beta(\varepsilon-0.25)}+2 e^{-\beta(\varepsilon+0.25)}-e^{-\beta \varepsilon}}{z-e^{-\beta}}\right] \\
& \text { при } 0,25 \leq \varepsilon \leq 0,75 \text {; } \\
& U_{P C}^{*}(z, \varepsilon)=\frac{K_{0}\left(1-\beta \overline{T_{E}}\right)}{\beta^{3}}\left[1-\frac{z e^{-\beta \varepsilon}-2 e^{-\beta(\varepsilon-0.25)}+2 e^{-\beta(\varepsilon-0.75)}-e^{-\beta \varepsilon}}{z-e^{-\beta}}\right] \\
& \text { при } 0,75 \leq \varepsilon \leq 1 \text {. }
\end{aligned}
$$

Для сталого режиму $(\mathrm{Z}=1)$ з $(3)$ для $\quad \varepsilon=0$

$$
U_{P C}(1,0)=\frac{K_{0}\left(1-\beta \overline{T_{E}}\right)}{\beta^{3}} \frac{\left(1-e^{-\beta}+2 e^{-0.75 \beta}-2 e^{-0,25 \beta}\right)}{1-e^{-\beta}} .
$$

Для $\varepsilon=0,25$, де $U_{P C}(1,0,25)=\frac{K_{0}\left(1-\beta \overline{T_{E}}\right)}{\beta^{3}}$ th $0.25 \beta$ th $0.25 \beta=\frac{e^{0,25 \beta}-e^{-0,25 \beta}}{e^{0,25}+e^{-0,25 \beta}}$.

3 (4) для $\varepsilon=0,25 U^{*}{ }_{P C}(1 ; 0,25)=\frac{K_{0}\left(1-\beta \overline{T_{E}}\right)}{\beta^{3}}$ th0.25ß,

для $\varepsilon=0,75 U_{P C}^{*}(1 ; 0,75)=-\frac{K_{0}(1-\beta \bar{T} E)}{\beta^{3}} t h 0.25 \beta$. 
3 (5) для $\varepsilon=0,75 U^{*} P C^{(1 ; 0,75)}=-\frac{K_{0}\left(1-\beta \overline{T_{E}}\right)}{\beta^{3}} t h 0.25 \beta$,

для $\varepsilon=1 U^{*} C^{(1 ; 1)}=-\frac{K_{0}\left(1-\beta \overline{T_{E}}\right)}{\beta^{3}} \frac{\left(1-2 e^{-\beta}+2 e^{-0.75 \beta}-2 e^{-0,25 \beta}\right)}{1-e^{-\beta}}$.

Відносний розмах пульсації від пика $(\varepsilon=0,25)$ до пика $(\varepsilon=0,25)$ з урахуванням значення $\mathrm{K}_{0}$ : де $U_{0}=U_{\mathcal{K}^{-}} E_{0}$.

$$
\Delta U^{*}{ }_{P C} \frac{\Delta U_{P C}}{U_{0}}=-\frac{8 \Delta I_{M} R\left(1-\beta \overline{T_{E}}\right)}{\beta \cdot n K_{C Y} U_{0}} t h 0.25 \beta .
$$

Амплітуда струму пилки $\Delta I_{M}$ залежить від $\alpha=\frac{T R}{L}$, де $\mathrm{R}-$ активний опір обмотки БДПС, $L=L_{S}+M$ - індуктивність фазної обмотки, яка дорівнює сумі індуктивності розсіювання та взаємоіндуктивності, Т - період роботи АIH.

Для $\alpha=1$ iї відносне значенння $\overline{\Delta I_{M}}=0,109 \frac{U_{0}}{R_{A}}$, постійний струм на вході АІН $I_{0}=\frac{0,5\left(U^{-E_{0}}\right)}{R}$, де $\mathscr{K}^{-}$напруга на виході КРІП-ПНС.

Для $T_{E}=0,015 c, K_{C V}=1, \alpha=1, R=10 м, T=0,25 \cdot 10^{-2} c$,

по (6) розраховано відносні залежності розмаху пульсацій на виході регулятора контуру струму від співвідношення $\frac{T_{C}}{T_{H}}$, для різних значень n. Результати представлено на рисунку 3.

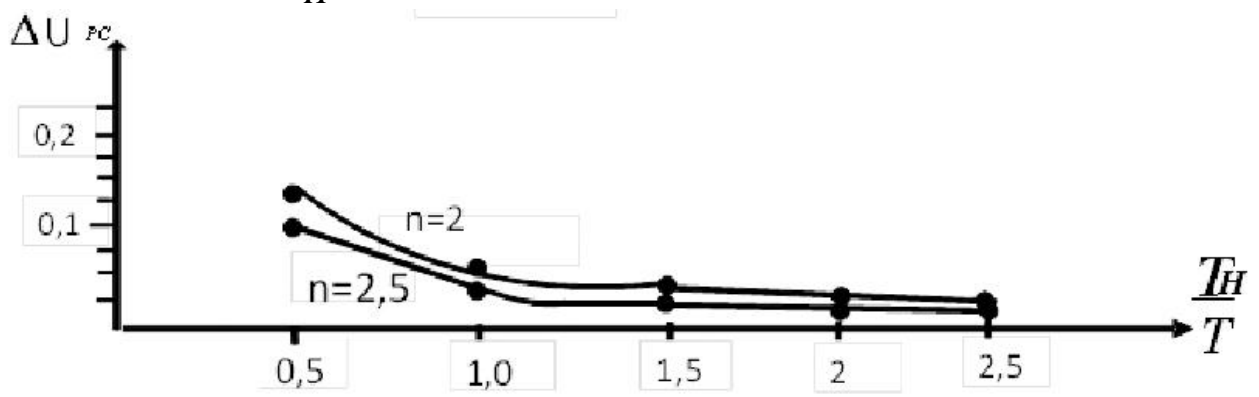

Рис.3. Відносні значення розмаху пульсацій

3 рисунку 3 бачимо, якщо $2 \leq n \leq 2,5$, то в діапазоні $1,5 \leq \frac{T_{H}}{T} \leq 2,5$ рівень пульсацій мінімальний. Збільшення нескомпенсованної постійної небажано за причиною збільшення затримки регулювання при незначному зниженні рівня пульсації, тому значення $2 \leq n \leq 2,5$ є оптимальним для співвідношення між постійною інтегрування регулятора контуру струму та некомпенсованою постійною.

Постійну інтегрування регулятора контуру струму можна знайти по результатах його налагодження на процес кінцевої тривалості без перерегулювання.

Висновки: Врахування дискретності комутатора дозволяє реалізувати у контурі струму системи електроприводу процес кінцевої тривалості без перерегулювання, за два періоди переналагодження частоти комутацій КРІП-ПНС. Мінімальний вплив пульсації на динаміку системи електроприводу БПЛА забезпечується, якщо відношення постійної інтегрування регулятора контуру струму до некомпенсованної постійної знаходиться в диапазоні $(2 \div 2,5)$. 


\title{
СПИСОК ЛІТЕРАТУРИ
}

1. Гребеников А.Г. Общие виды и характеристики беспилотных летательных аппаратов: справ. пособие / А.Г. Гребеников, А.К. Мялица, В.В. Парфенюк и др. - Х.: Нац. аэрокосм. ун-т “Харьковский авиационный институт”, 2008. - 377 с

2. Левин А.В. Электрический самолет: от идеи до реализации. / А.В. Левин, И.И. Алексеев, С.А. Харитонов, Л.К. Ковалев - М.: Машиностроение, 2010. - 288 с.

3. Овчинников И.Е. Вентильные электрические двигатели и электропривод на их основе. / И.Е. Овчинников. - Санкт-Петербург: Корона-Век, 2012, - 336 с.

4. Singh B., Singh S. Singl-phuse Power Factor Controller Topologies for Dermument Magnet Brushless DC Motor Drives. - IET Power Electronic, 2010, - vol.3. ISS. 2P. 147-175.

5. Антонов А.Е. Особенности построения электромеханической системы ориентации наноспутника на основе бесконтактного магнитоэлектрического двигателя. Технічна електродинаміка. / А.Е. Антонов, К.П. Акинин, В.Т. Киреев. - 2017. - №4. - С. 36-40.

6. Акинин К.П. Релейно-векторная система управления бесконтактными двигателями с постоянными магнитами с датчиком тока в звене постоянного тока. Технічна електродинаміка. / К.П. Акинин, - 2014. - №3. -С. 52-55.

7. Денисов Ю.О. Системи перетворювальної техніки. / Ю.О. Денисов. - Чернігів: ЧНТУ, 2014. $-170 \mathrm{c}$.

8. Лебедев Е.Д. Управление вентильными електроприводами постоянного тока. / В.Е. Неймарк, М.Я. Пистрак, О.В. Слежановский. - М.: Энергия, 1970, - 232 с.

\section{Денисов Юрій Олександрович}

доктор технічних наук, професор, провідний науковий співробітник Державного науково-дослідного інституту випробувань і сертифікації озброєння та військової техніки, Чернігів, Україна http://orcid.org/0000-0003-2293-7964 $+38067-460-08-81$

\section{Denisov Yuriy}

Doctor of Technical Sciences, Professor, Lead Researcher of State Scientific Research Institute of Armament and Military Equipment Testing and Certification, Chernihiv, Ukraine http://orcid.org/0000-0003-2293-7964 $+38067-460-08-81$

\section{PULSATING IMPACT ON THE CONSTANT INTEGRATION OF CURRENT LOOP REGULATOR OF QUADROCOPTER ELECTRICAL DRIVE SYSTEM Y. Denisov}

\begin{abstract}
The growing role of drones in military applications is raising the urgent problem of improving their energy efficiency and control quality. The article proposes the solution of the issue of increasing the energy efficiency of the control systems of the electric drive, reducing the losses of electric power on board the robotic complex, this is one of the main directions of further impruvment of robotic technical systems of special and civil purpose. Control systems for electric drives with improved dynamic and energy performance are intended for use in stabilization systems for unmanned aerial vehicles. Particular attention is paid to the development of the run time of autonomous robotic complexes under conditions of limited capacity of the primary power source. As a device for converting electric energy into motion, non-collector motors of direct current are used, which switches a pulse-width modulation form of the output voltage in the best predetermined manner to realize optimal processes of consumption of the current of the onboard battery, which provides energy saving. The basic scientific approaches outlined in the article will allow to increase the energy efficiency of electric drive systems of robotic complexes and electromechanical manipulators by optimizing the regulation processes. The analysis of the level of voltage ripples at the input of the control system of a quasi-resonant pulse converter that switches at zero current is carried out. It regulates the voltage at the input of the autonomous voltage inverter in the drone's electric drive system. The relation between the constant integration of the current loop regulator and the uncompensated constant is obtained, in which the pulsations at the input of the control system are minimal. With the setting of the current loop regulator in the process of finite duration, the optimal value of this ratio is obtained.
\end{abstract}

Keywords: discrete, ripple currents, Z-transform, current loop, optimization, collector free DC motor. 